\title{
Effect of Theory-Based Education on the Promotion of Preventive Behaviors of Accidents and Injuries among Mothers with Under-5-years-old Children
}

\begin{abstract}
Background and objective: The first leading cause of death among the first 5 years of children' life around the world are accidents and injuries. The aim of this study was to determine the effect of theory-based education on the promotion of preventive behaviors in accidents and injuries among mothers with children under 5 years old.

Materials and methods: This was a quasi-experimental study that was carried out on 130 mothers of children less than 5 years referred to health centers in Khorramabad in 2014. Data was collected using a four parts questionnaire (demographic data, knowledge, health belief model structures and performance). The case group participated in two health education sessions with 50 minutes duration. Data was collected before and three month after education among the two groups. The data was analyzed using descriptive statistics (medium, SD, and frequency) and analytical statistics (Kolmogorov-Simonov test, Wilcoxon test, and Mann-Whitney test) through SPSS20.

Results: Before the intervention, the mean score of knowledge, components of the health belief model and performance had no significant difference among the two groups before intervention. But after intervention, it was significant $(p<0.01)$. The mean score of performance in case group from 52.3 to 69.53 significant increased after intervention $(p<00.1)$.

Conclusion: According to the increase amount obtained from the structure, based on theory and implementation of a training program based on health belief model among mothers of children under 5 years old with active pursuit to improve their performance in the prevention of accidents and injuries in children.

Paper Type: Research Article.

Keywords: Health Belief Model (HBM), Children health, Accidents, Child injury prevention, Interventional education, Khorramabad.
\end{abstract}

Citation: Fathi Shyikhi M, Shamsi M, Khorsandi M. Effect of theory-based education on the promotion of preventive behaviors of accidents and injuries among mothers with under-5-years-old children. Iran J Health Educ Health Promot. Autumn 2016;4(3): 184-193.

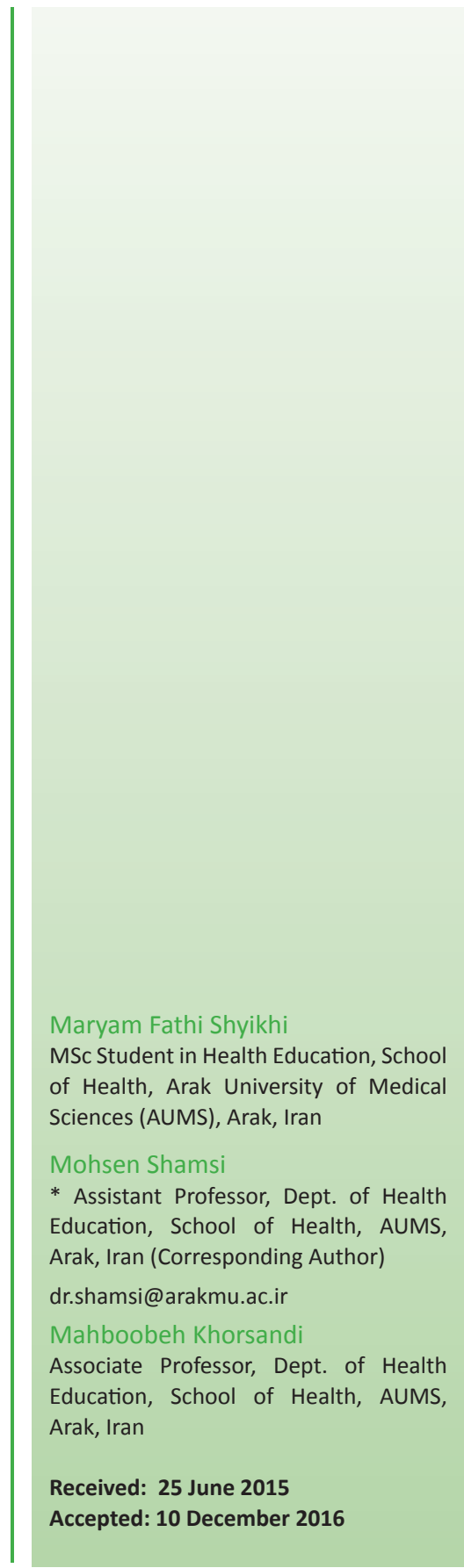


مريم فتحشيخى دانشجوى كارشناسى ارشد آموزش بهداشت، دانشكده

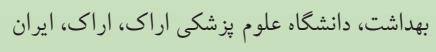

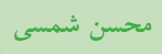

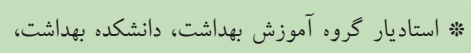

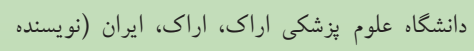

مسئول) dr.shamsi@arakmu.ac.ir

محبوبيه خورسندى

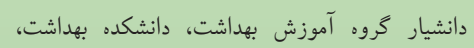

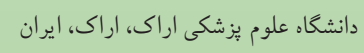

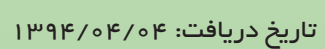

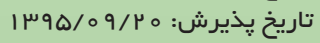

\section{0}

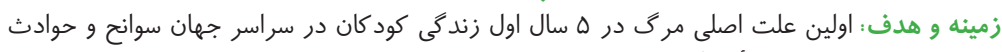

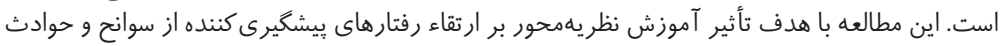

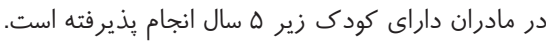

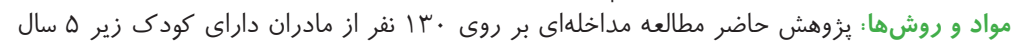

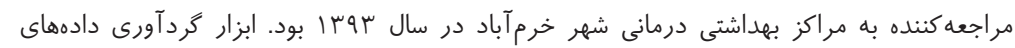

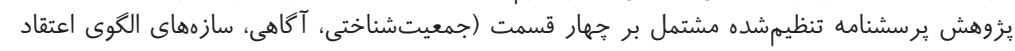

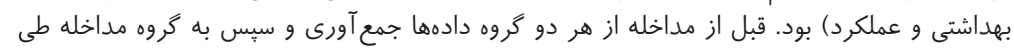

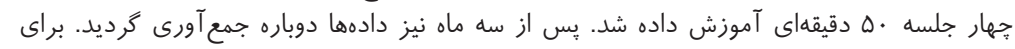

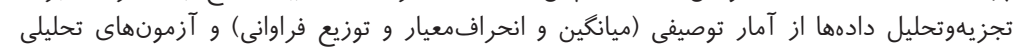

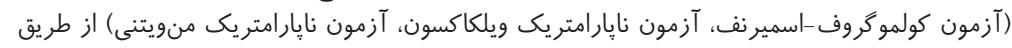
PSSr.

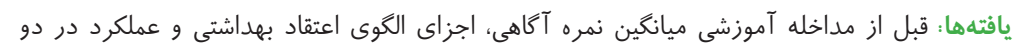

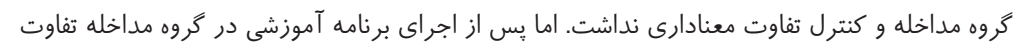

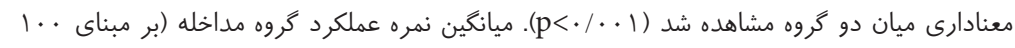

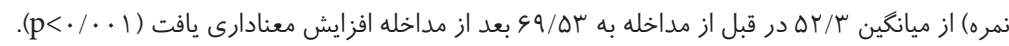

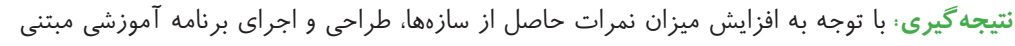

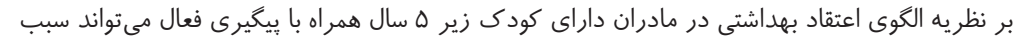

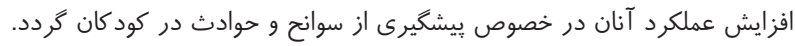

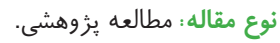

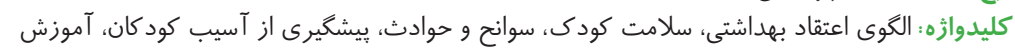
مداخلهاى، خرم آباد.

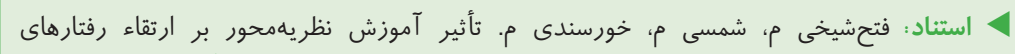

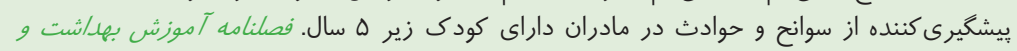


بهطورى كه ميزان مرگ كودكان زير ها سال از FF در هزار تولد

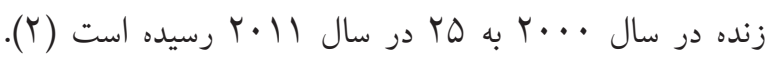
نكته قابلتوجه در موضوع قابل بيشخيرى و ويش بيش بينى بودن آن

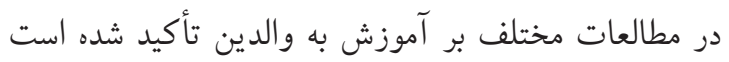

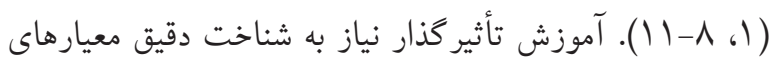
نكرشى و رفتارى گروه مخاطب دارد. اين امر از طريق به كاركيرى الخوهاى آموزشى تا حدودى ميسر است. به كونهاى

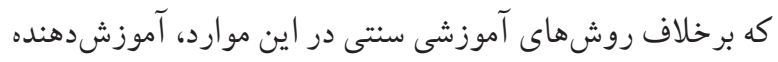

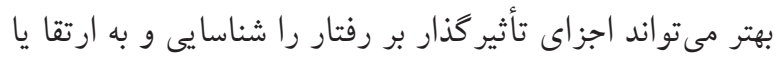

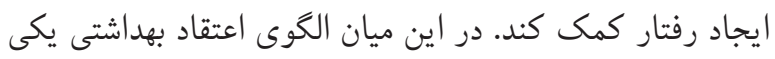
از قديمىترين و اولين نظريههاى علوم رفتارى است كه هنوز

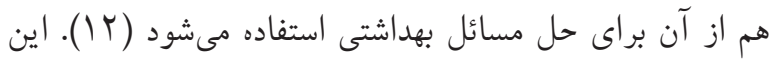

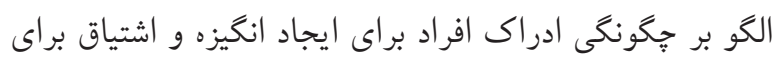

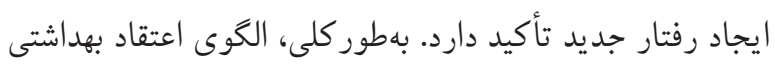

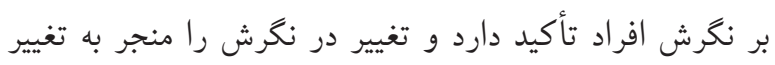
رفتار مىداند (1/). الخوى اعتقاد بهداشتى يكى از الخوهايى است كه در راستاى لهاى

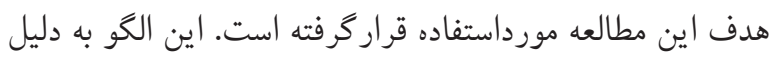
اهميت موضوع و لزوم اقدام به عمل براى بيشخيرى از سوانح و

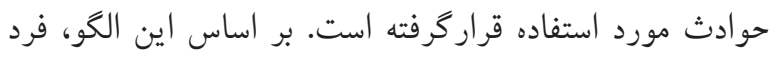

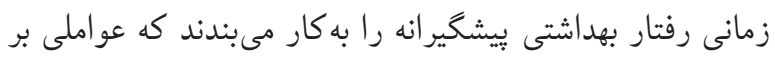

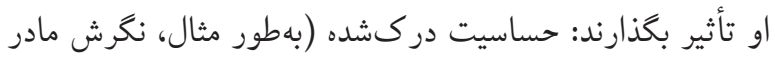
در خصوص اينكه كودى وى ممكن است در معرض سوانح و حوادث قرار گيرد)، شدت دركشده (بهطور مثال، بروز سوانح و حوادث در كودى من باعث ناتوانى موقت در فعاليتهاى

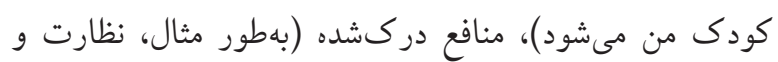

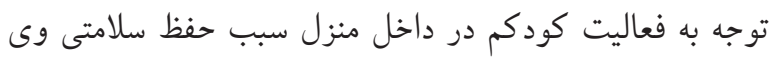

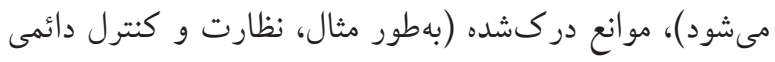
فعاليتهاى كودكم مرا خسته مى كند)، راهنماى عمل (بهطور

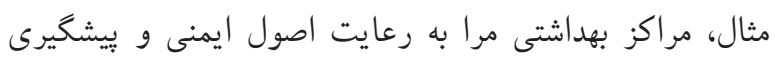

يكى از شاخصهاى مهم ارزيابى ميزان توسعهيافتكى كشورها ميزان مرگومير كودكان زير ه سال است ( (1). اين مرگها مها عمدتاً

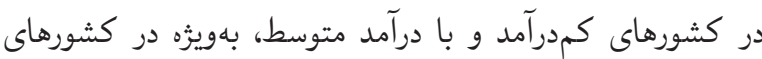
صحراى آفريقا و جنوب آسيا، اتفاق مى افتد (Y). حوادث دراث همواره

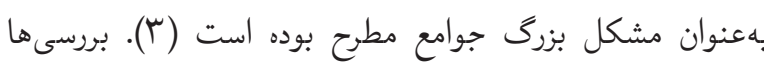

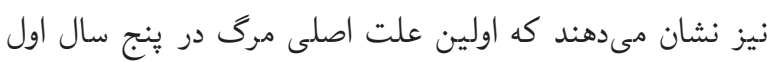
زندگى كودكان سراسر جهان سوانح و حوادث است؛ كه بيش از 90 ٪ آسيبها در كودكان در كشورهاى با سطح درآمد كم و متوسط رخ مى دهد (†). سوانح و حوادث مى تواند از عمدهترين علت مرگ و معلوليت مادامالعمر در كودكان بوده و كودكان مونان

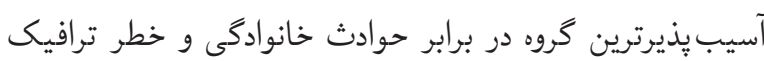
محسوب مى شوند(ب).

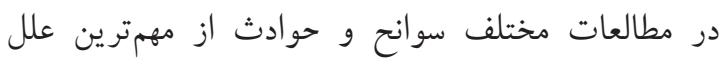
مرگ مير كودكان مطرحشده است (Q-V)). درصورتى كه دامنه توجه به ييامدهاى سلامتى ناشى از حوادث وسيع تر گردد، ملاحظه

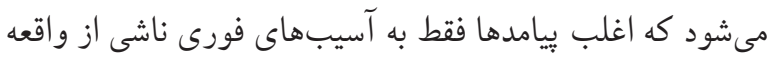
محدود نمى گردد. هر حادثه منجر به آسيب جسمانى در بيشتر

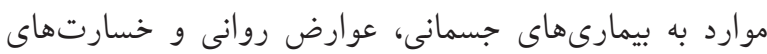

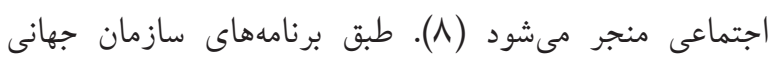

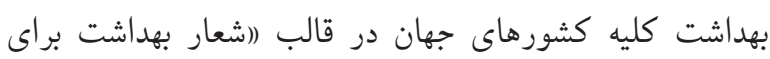
همهة) متعهد به بهبود سلامت كودكان هستند و نيمى از كشورهاى

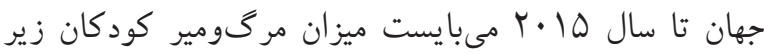

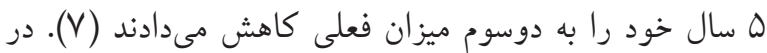

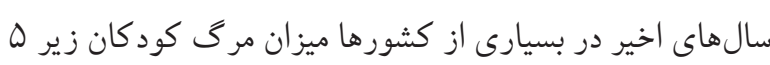

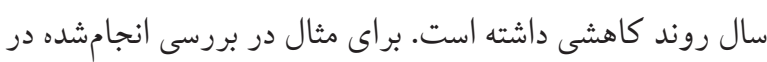
1 AV

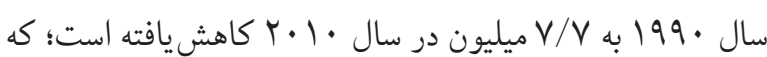

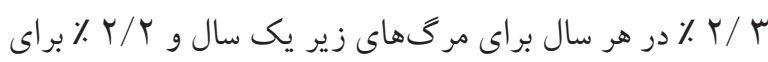

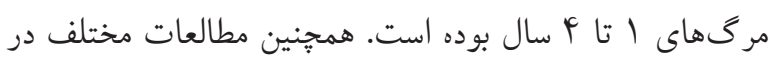
ايران دلالت بر كاهش مرى كودكان در سالهاى اخير مى كند. 
خودگزارشدهى و با استفاده از يرسشنامه استاندارد برگرفته از

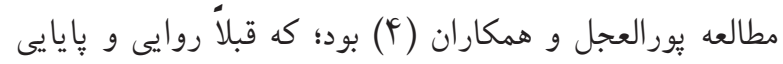
آن مورد تائيد قرار كرفته است. اين يرسشنامه شامل، اطلاعات

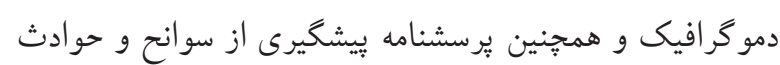

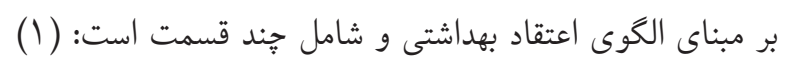

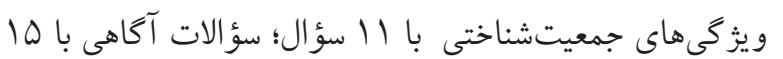
سؤال؛ (ץ) سؤالات ابعاد مختلف الكوى اعتقاد بهداشتى شامل:

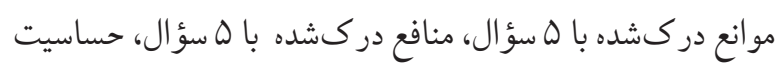

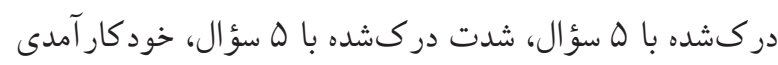

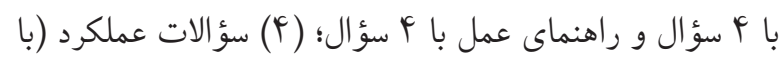

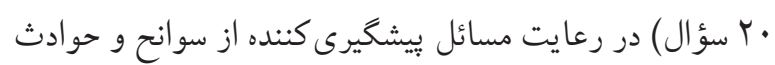

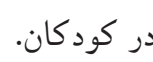
نحوه امتيازدهى برسشنامه بدينصورت بود: در قسمتهاى

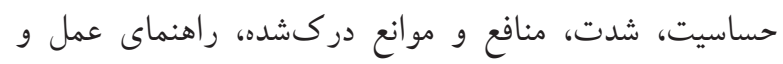

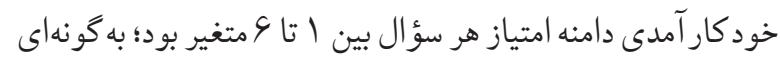

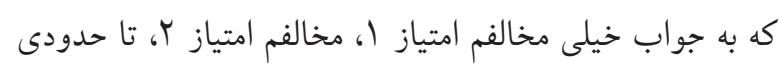

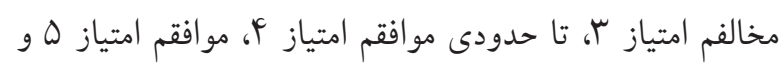

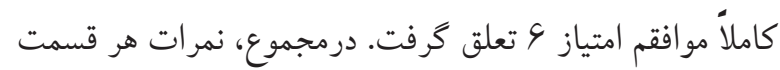

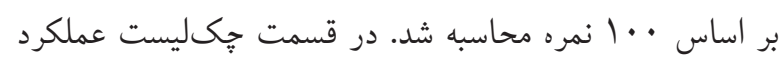

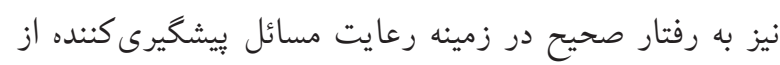

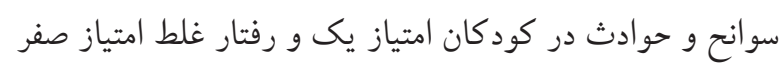

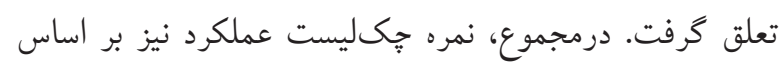

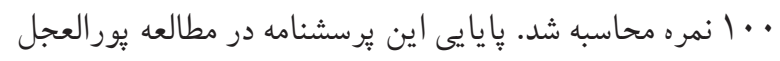

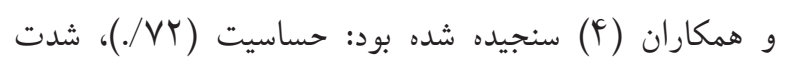
( ) ( راهنماى عمل (VT/.)؛ كه قابلقبول بود.)، موانع آلفاى كرونباخ كل

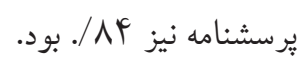

ڤِ از جمع آورى دادهها، در قبل از مداخله آموزشى و بر برد

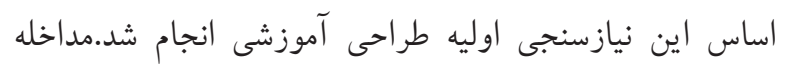

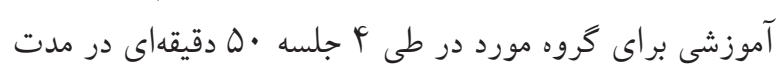

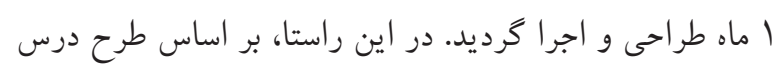

از آسيبديدگى كودكان توصيه مى كنند)، خودكار آمدى (بهطور مثال، اطمينان دارم كه مىتوانم بر فعاليتهاى كودكم در هرد زمان نظارت و توجه كافى داشته باشم). از آنجائى كه كودكان

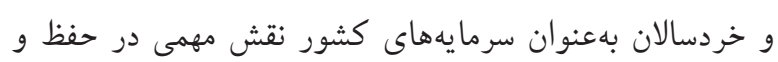

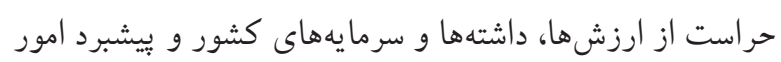

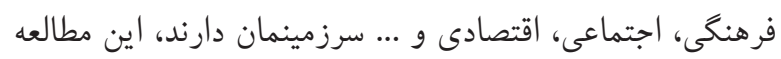
بهمنظور بررسى تأثير آموزش بر مبناى الخوى اعتقاد بهداشتى بر وني

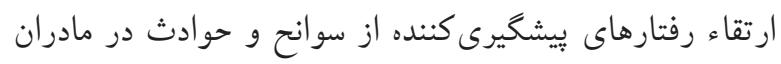
داراى كودى زير ه سال صورت كرفت.

$$
\text { مو اد و روشها }
$$

اين مطالعه تجربى و از نوع كارآزمايى شاهددار بود. جامعه آن

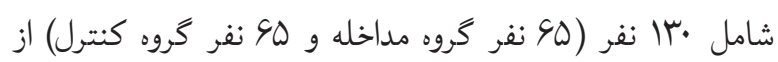

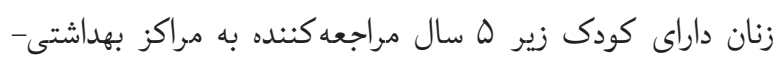
درمانى شهر خرمآباد در بوسا بود. براى نمونه گيرى ابتدا شهر مراج

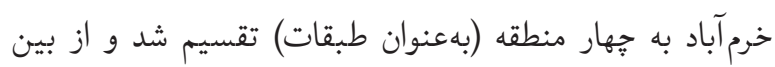
المركز بهداشتى درمانى موجود در هر منطقه (بهعنوان خوشهها)، دو مركز بهصورت تصادفى انتخاب شدند؛ يك مركز بهعنوان

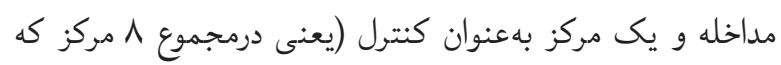

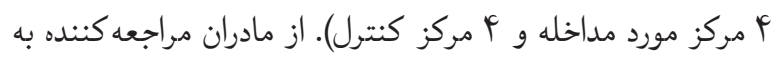

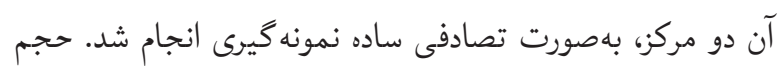

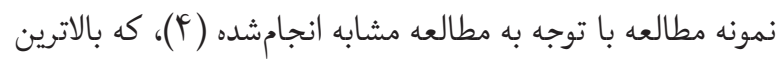

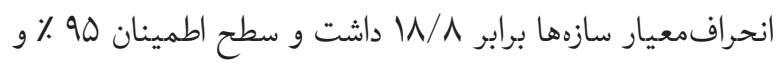

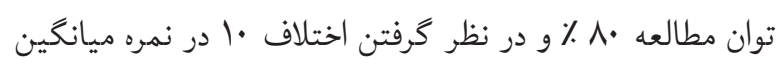

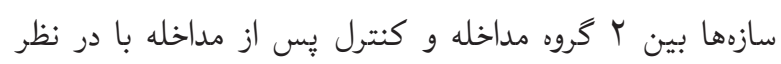

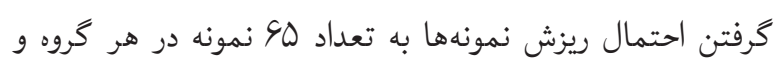
درمجموع •سا نمونه در نظر كرفته شد. فرمول محاسبه حجم نمونه به شكل زير است: $n=\frac{\left(s_{1}^{2}+s_{2}{ }^{2}\right)\left(z_{1-\frac{\alpha}{2}}+z_{1-\beta}\right)^{2}}{\left(\bar{x}_{1}-\bar{x}_{2}\right)^{2}}$

در اين مطالعه نحوه جمع آورى دادهها از طريق 
جمعيتشناختى كروه مورد و شاهد از آزمون تى استفاده شد. اما

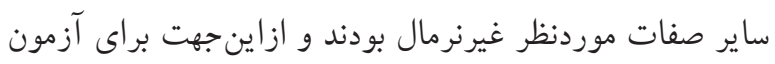

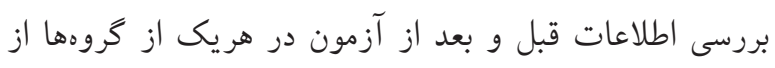

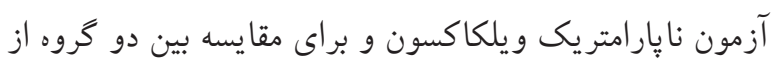
آزمون نايارامتر يك منويتنى استفاده شد.

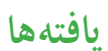

ه/OV ميانكين سنى كروه مداخله و كنترل به ترتيب برابر 政 مادران خانهدار بودند. بيشترين آنان تحصيلات دييلم داشتند:

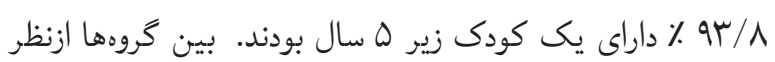

اين متغيرها تفاوت معنادار مشاهده نشد (جداول او و Y ب).

جدول ا. ميانگين و انحرافمعيار سن مادر، سن كودى، تعداد كودكان زير ه سال، تعداد فرزندان خانواده در دو كَروه مداخله و كنترل

\begin{tabular}{|c|c|c|c|c|c|}
\hline \multirow[b]{2}{*}{ آزمون تى } & \multicolumn{2}{|c|}{ گروه شاهد } & \multicolumn{2}{|c|}{ كروه مورد } & \\
\hline & انحراف & ميانكين & انحراف & ميانگين & \\
\hline $\mathrm{p}=\cdot / 9 \mu \wedge$ & $\Delta / V T$ & $r q / r V$ & $\Delta / \Delta V$ & $r q / r$ & سن مادر (سال) \\
\hline $\mathrm{p}=\cdot / \mu \wedge F$ & $1 F / 99$ & $19 / \pi 0$ & $19 / 40$ & $r I / V \mu$ & سن كودى (ماه) \\
\hline $\mathrm{p}=1$ & $\cdot / \mu^{r}$ & $1 / .4$ & $\cdot / T F$ & $1 / .9$ & تعداد كودك زير \\
\hline $\mathrm{P}=\cdot / \Lambda \Lambda$ & $1 / 10$ & $1 / \wedge 1$ & $|/ r|$ & l/AF & تعداد فرزندان \\
\hline
\end{tabular}

جدول r. توزيع فراوانى مطلق و نسبى تحصيلات افراد موردمطالعه

بر حسب وضعيت تحصيلات و جنسيت كودى ولى سوريلات

\begin{tabular}{|c|c|c|c|c|}
\hline \multirow{2}{*}{ كاى آزمكوئر } & \multirow{2}{*}{ تعداد (درصد كروه } & \multirow{2}{*}{ تعدوه مورد } & \multirow{2}{*}{\multicolumn{2}{|c|}{ متغير هاى جمعيتشناختى }} \\
\hline & & & & \\
\hline \multirow{5}{*}{$\mathrm{p}=\cdot / \mu \checkmark \mid$} & $(1 \% / \Lambda) q$ & $1 \cdot(\mid \Delta / \mathcal{F})$ & ابتدايى & \multirow{5}{*}{ تحصيلات مادر } \\
\hline & $f(s / 1)$ & $(\mid r / \mu) \Lambda$ & راهنمايى & \\
\hline & $V(1 \cdot / \Lambda)$ & $q(9 / r)$ & (دبير ستان) & \\
\hline & r人 (Fr/l) & $(\mathcal{F} / \mathrm{V}) \boldsymbol{N}^{\mathrm{\mu}}$ & دييلم & \\
\hline & $\mid V(r G / Y)$ & $1 \cdot(10 / \mathcal{F})$ & دانشخاهى & \\
\hline \multirow{2}{*}{$\mathrm{p}=\cdot / \mathcal{\vee} \vee q$} & $\mu \cdot(\mathcal{F} \in / \Gamma)$ & $r \varphi(r \cdot)$ & دختر & \multirow{2}{*}{ كنسيت } \\
\hline & $r \Delta(\Delta \mu / \Lambda)$ & $\mu q(\xi \cdot)$ & קֶ, & \\
\hline
\end{tabular}

تدوينشده و بر اساس نيازسنجى اوليه بيشترين موارد ضعف

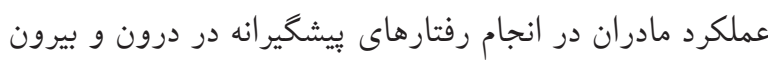
منزل موردبررسى و در قالب آموزش حضورى، اسلايد، فيلم

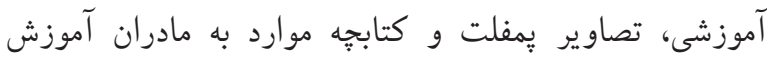

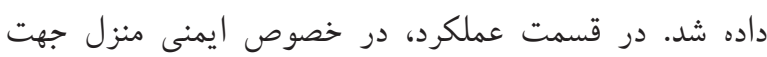

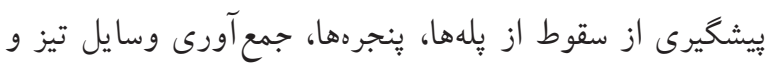

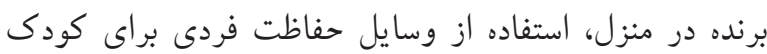
در هنكام بازى و غيره آموزش داده شد. آموزشها با با استفاده از روشهاى سخنرانى، بحث كروهى، دادن كتابهه آموزشى و

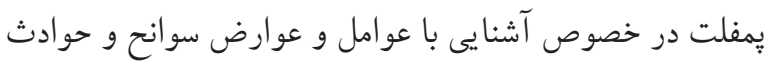

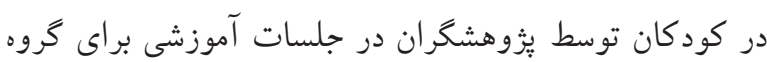
مداخله انجام شد. انجام يِ آزمون از طريق توزيع مجدد يِرسشناهه در كروه

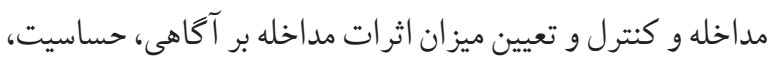

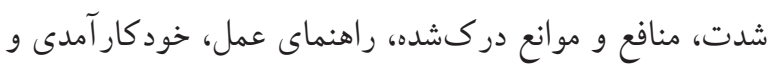
عملكرد در خصوص يبشكيرى از سوانح و حوادث در كودكان

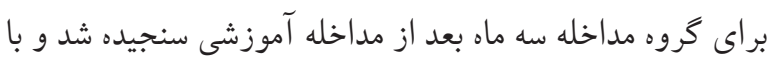
كروه كنترل مقايسه كرديد.

مطالعه حاضر قبل از اجرا در كميته اخلاق يُّوهش دانشكاه

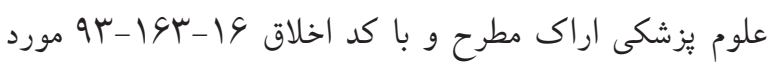
تصويب رسيد. همجينين قبل از انجام مداخله نيز ضمن بيان اهداف مطالعه رضايت شفاهى از نمونهها اخذ و شركت در مطالعه

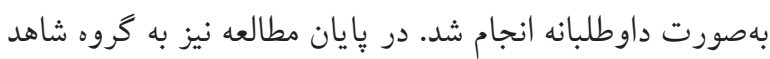
يمفلت آموزشى ارائه شده است.

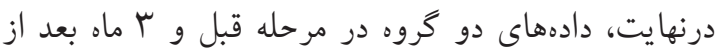

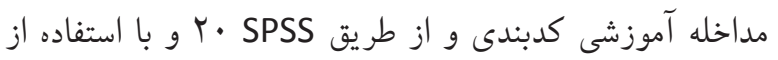
آمار توصيفى (ميانكين و انحر افمعيار و توزيع فراوانى) و و آمار

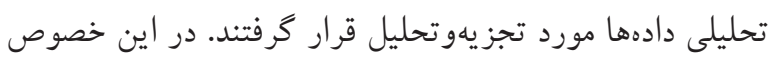

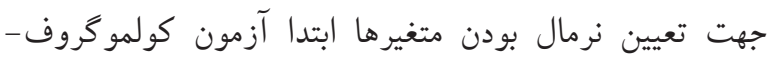
اسميرنف انجام شد؛ كه طبق اين آزمون تمامى صفات بردات جمعيتشناختى نرمال بود و ازاينجهت براى مقايسه اطلاعات آنات 
جدول س. ميانگين نمرات آكاهى و سازههاى الگُى اعتقاد بهداشتى در خصوص رفتارهاى ييشگيرى كننده از سوانح و حوادث در قبل و سه

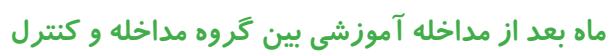

\begin{tabular}{|c|c|c|c|c|c|c|}
\hline \multirow{2}{*}{ نتيجه آزمون ويلكاكسون } & \multicolumn{2}{|c|}{ سه ماه بعد از مداخله } & \multicolumn{2}{|c|}{ قبل از مداخله } & \multirow{2}{*}{ كروه } & \multirow{2}{*}{ 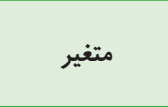 } \\
\hline & انحرافمعيار & ميانغين & انحرافمعيار & ميانگين & & \\
\hline $\mathrm{p}<\cdot / \cdots 1$ & $11 / 1$ & $\Lambda \cdot|9|$ & $1 r / v q$ & $\Delta 1 / Y \Lambda$ & مداخله & \multirow{3}{*}{ آكاهى } \\
\hline \multirow[t]{2}{*}{$\mathrm{p}-$ value $=\cdot / \Delta s$} & $1 \cdot / 90$ & $\Delta 1 / \mu^{\prime}$ & $11 / 19$ & $\Delta r$ & كنترل & \\
\hline & \multicolumn{2}{|c|}{$\mathrm{p}<\cdot / \cdots 1$} & \multicolumn{2}{|c|}{$\mathrm{p}=. / 9 \wedge 9$} & نتيجه آزمون منويتنى & \\
\hline $\mathrm{p}<\cdot / \cdot \cdot 1$ & $\mid F / \Lambda s$ & $\vee q / \mu r$ & $1 r / 19$ & $s V / V F$ & مداخله & \multirow{3}{*}{ دركشدهيت } \\
\hline $\mathrm{p}=\cdot / \varepsilon V^{F}$ & $1 \% / 1$ & Sq/rr & $1 r / 90$ & SV/rr & كنترل & \\
\hline & \multicolumn{2}{|c|}{$\mathrm{p}<\cdot / \cdot \cdot 1$} & \multicolumn{2}{|c|}{$\mathrm{p}=\cdot / 94 \mid$} & نتيجه آزمون منويتنى & \\
\hline $\mathrm{p}<\cdot / \cdots 1$ & $N / \cdot V$ & $11 / 9 F$ & $1 \cdot / \mu r$ & $90 / \wedge 9$ & مداخله & \multirow{3}{*}{ شدت درك شده } \\
\hline $\mathrm{p}=\cdot / \mu \mathrm{IV}$ & $9 / \vee \wedge$ & s9/9V & $1 . / 11$ & $S V / I T$ & كنترل & \\
\hline & \multicolumn{2}{|c|}{$\mathrm{p}<\cdot / \cdots 1$} & \multicolumn{2}{|c|}{$\mathrm{p}=\cdot / \mu$} & نتيجه آزمون منويتنى & \\
\hline $\mathrm{p}<\cdot / \cdot \cdot 1$ & $s / f r$ & $9 \cdot / 01$ & $N / F r$ & $\Lambda \mu / g r$ & مداخله & \multirow{3}{*}{ منافع دركشده } \\
\hline $\mathrm{p}=\cdot / \cdot \Delta \mathrm{V}$ & $V / f$ & $\Lambda r / G r$ & $V / g \mu$ & $\Lambda \mu / \cdot \vee$ & كنترل & \\
\hline & \multicolumn{2}{|c|}{$\mathrm{p}<\cdot / \cdot \cdot 1$} & \multicolumn{2}{|c|}{$p=\cdot / 9 q r$} & نتيجه آزمون منويتنى & \\
\hline $\mathrm{p}<\cdot / \cdot \cdot 1$ & $\mid r / \cdot r$ & $\Delta \cdot / \wedge \mathrm{V}$ & S/Or & $S V / F r$ & مداخله & \multirow{3}{*}{ موانع دركشده } \\
\hline $\mathrm{p}-$ value $=\cdot / 1$ & $1 \cdot / v 9$ & $99 / 91$ & $\Delta / 9 \vee$ & SF/VG & كنترل & \\
\hline & \multicolumn{2}{|c|}{$\mathrm{p}<\cdot / \cdot \cdot 1$} & \multicolumn{2}{|c|}{$\mathrm{p}=\cdot / \Delta$} & نتيجه آزمون منويتنى & \\
\hline $\mathrm{p}<\cdot / \ldots 1$ & $V / s$ & $V \wedge / F S$ & $q / 4 q$ & SV/VO & مداخله & \multirow{3}{*}{ خود كار آمدى } \\
\hline $\mathrm{p}-$ value $=\cdot / \uparrow \Delta$ & $N / F \Delta$ & S9/9T & $V / S$ & $S V / F r$ & كنترل & \\
\hline & \multicolumn{2}{|c|}{$\mathrm{p}<\cdot / \cdot \cdot 1$} & \multicolumn{2}{|c|}{$\mathrm{p}=\cdot / 9 \mu q$} & نتيجه آزمون منويتنى & \\
\hline $\mathrm{p}<\cdot / \cdot \cdot 1$ & N/1 & N1/Or & $1 \cdot / r \Lambda$ & $V 1 / 4$ & مداخله & \multirow{3}{*}{ راهنماى عمل } \\
\hline $\mathrm{p}=\cdot / T \vee \mathrm{V}$ & N/FG & $V r / v i$ & $\Lambda / \mu$ & $\mathrm{Vr} / 9 \mathrm{~V}$ & كنترل & \\
\hline & \multicolumn{2}{|c|}{$\mathrm{p}<\cdot / \cdot \cdot 1$} & \multicolumn{2}{|c|}{$\mathrm{p}=\cdot / 19 \mathrm{r}$} & نتيجه آزمون منويتنى & \\
\hline $\mathrm{p}<\cdot / \cdot \cdot 1$ & $11 / 94$ & sq/Dr & $1 \cdot 1 \cdot 1$ & $\Delta r / \mu$ & مداخله & \multirow{3}{*}{ عملكرد } \\
\hline $\mathrm{p}=\cdot / 14$ & $11 / 49$ & $r q / 4 \mu$ & $1 \cdot / 19$ & $0 \cdot / 9 r$ & كنترل & \\
\hline & \multicolumn{2}{|c|}{$\mathrm{p}<\cdot / \cdots 1$} & \multicolumn{2}{|c|}{$\mathrm{p}=\cdot / 010$} & نتيجه آزمون منويتنى & \\
\hline
\end{tabular}

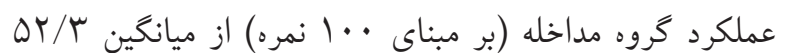
در قبل از مداخله به سوهو بعد از مداخله افزايش معنادارى

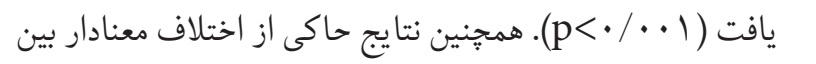
ميانخين نمرات متغيرهاى موردنظر در گروه مداخله قبل و بعد

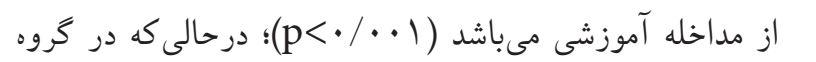
كنترل هيج گونه اختلاف معنادارى قبل و بعد از مداخله مشاهده

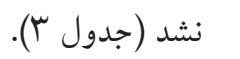

ميانگين نمرات متغيرهاى آكاهى، حساسيت دركشده، شدت دركشده، منافع دركشده، موانع دركشده، خودكارآمدى، راهنماى عمل و عملكرد در خصوص سوانح و حوادث در كود كان زير ه سال در دو گروه مداخله و كنترل در جدول لانشان داده شده است. يافتها نشان داده است كه قبل از مداخله آموزشى هيج گونه اختلاف معنادارى در دو گروه ازلحاظ متغيرهاى نامبرده وجود ندارد. اما يس از مداخله آموزشى بين دو گروه ازلحاظ متغيرهاى نامبرده اختلاف معنادارى يافت شد ( ( • • p p). ميانگين نمره 
استفاده شد. در مطالعات مختلف نيز بر تأثير ارتقاء حساسيت و

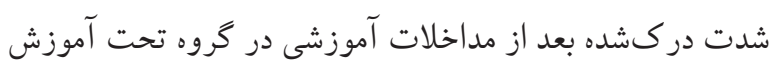

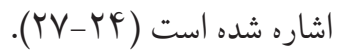

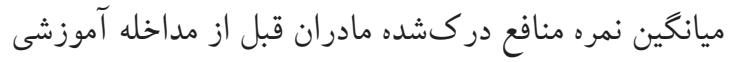

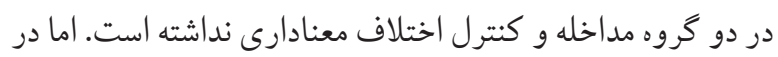

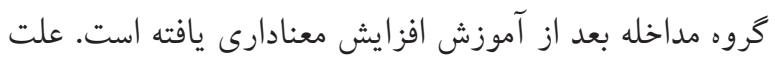

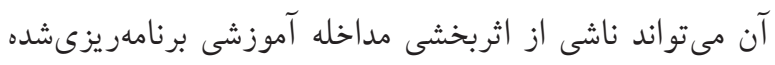
در افزايش منافع دركشده مادران تحت مداخله آموزشى باشد.

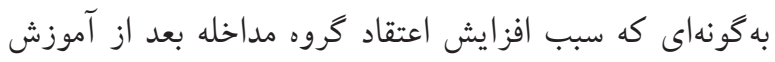
در خصوص منافع حاصل از انجام رفتارهاى بيشخيرى كننده شده است. ازجمله اينكه مادران اعتقاد بيشترى به اين موارد داشتند:

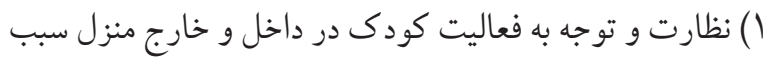
حفظ سلامتى كودى مىشود؛ Y) توجه به توصيههاى ارائهده

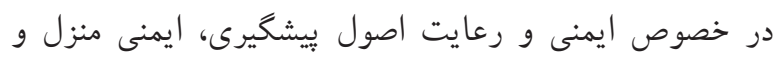

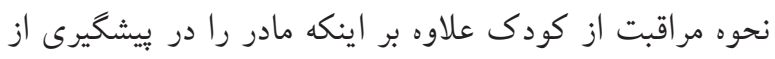

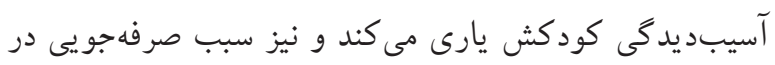

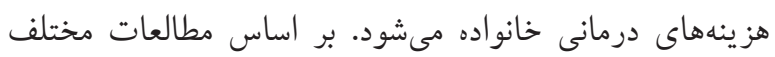
رابطه مستقيمى بين افزايش منافع دركشده و اتخاذ رفتارهاى

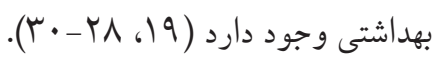

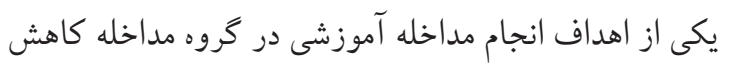
موانع دركشده بود. اين موضوع در اين مطالعه محقق شد.

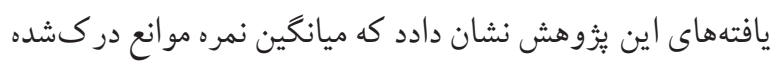

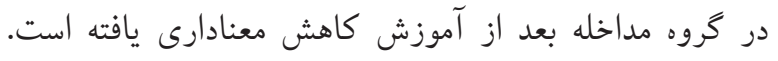

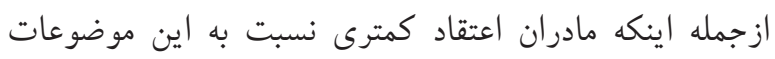
داشتند: نظارت و كنترل دائمى فعاليتهاى كودكم وقت كير و خسته كننده است، ايمنسازى منزل (نصب حفاظ ينجره، نرده و ...) يرهزينه و وقت گير است و رسيدگى به ساير امور منزل نيز آنها را از توجه و مراقبت كافى نسبت به كود كانشان باز

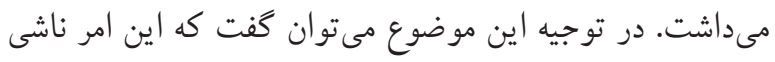
از اثربخشى مداخله آموزشى برنامهريزىشده در كاهش مورئ موانع دركشده مادران تحت مداخله آموزشى بود. بنابراين، اين مطلب مدري

در اين مطالعه ميانگين نمره آكاهى مادران قبل از مداخله آموزشى

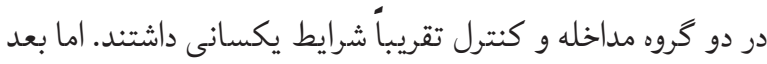
از مداخله اين افزايش در كروه مداخله نسبت به كنترل مشاهده

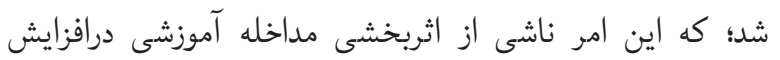

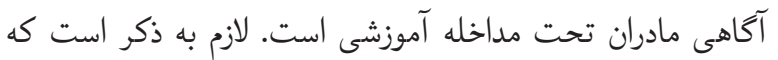

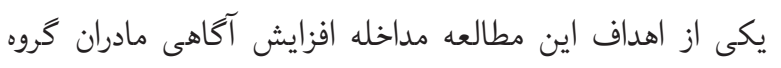

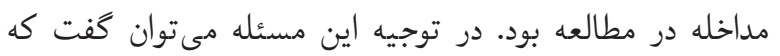
تشكيل كلاس هاى آموزشى در مراكز بهداشتى درمانى براى مادران تا حدودى توانسته سبب ارتقاء ميزان آكاهى مادران در مورد رفتار

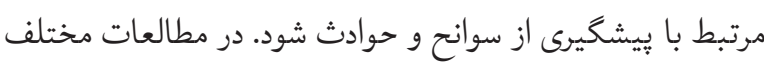
بر لزوم آموزشهاى سوانح و حوادث در كودكان به والدين خصوصاً

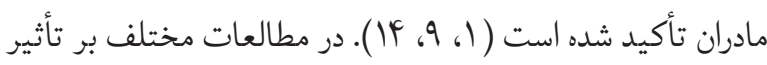

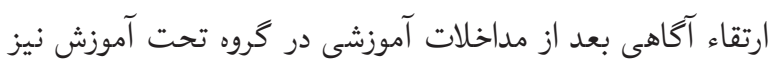

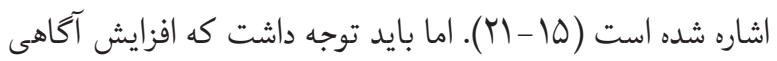
بهتنهايى نمىتواند موجب تغيير در عملكرد گردد. بنابراين، جهت تغيير عملكرد علاوه بر آكاهى بايد بر روى نكرش افراد نيز مداخلاتى انجام شود. در مطالعات مختلف به اين امر اشاره

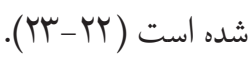

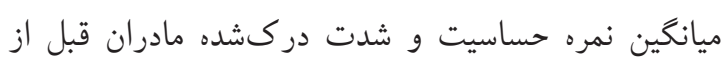
مداخله آموزشى در دو كروه مداخله و كنترل اختلاف معنادارى نداشتند؛ اما بعد از مداخله آموزشى در كروه درو مداخله ميانكين نمره مدره

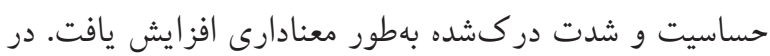
توجيه اين موضوع مىتوان كفت كه اين امر ناشى از اثربخشى

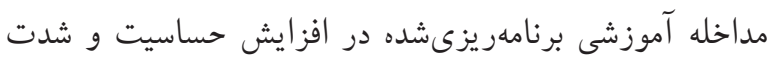
دركشده مادران تحت مداخله آموزشى است. به گونهاى كه سبب

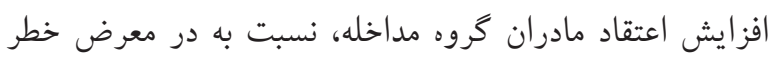

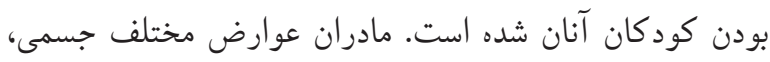
روانى، اجتماعى و اقتصادى ناشى از بروز سوانح و حوادث دود درد

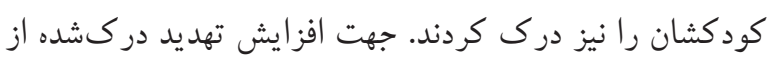
روش سخنرانى، بحث گروهى و اجراى سناريوى مرى كودى 
برنامهريزىشده در افزايش راهنماى عمل مادران تحت مداخله

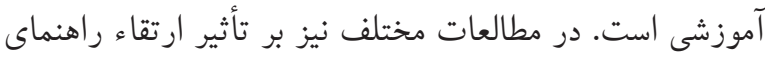

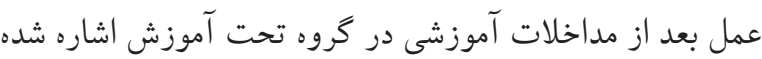

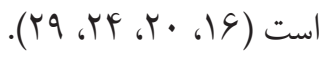

در مطالعه حاضر هر جقدر عملكرد مادر بيشتر باشد بيانكر انجام رفتارهاى بيشخيرى كننده بهترى از طرف مادر مى باشد.

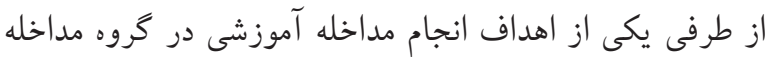

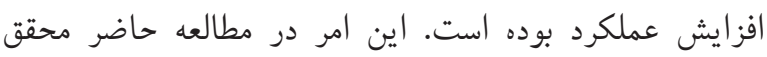

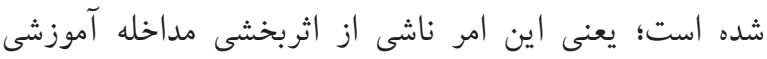

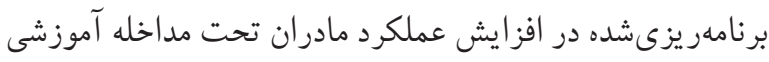

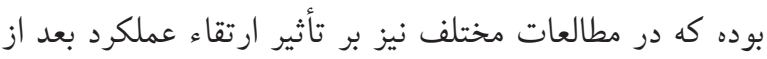

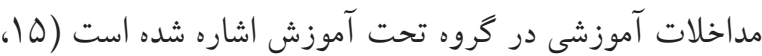

تتيجه كيرى: بهطوركلى نتايج يُوهش حاضر نشان داد كه

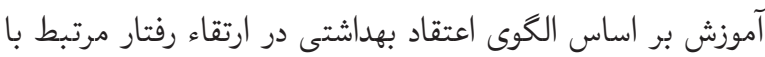
ييشخيرى از سوانح و حوادث در كودكان مؤثر بوده است. همجنين

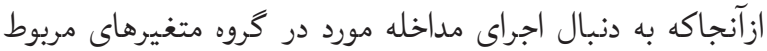

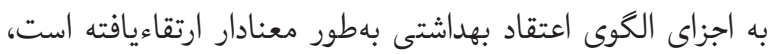
مى توان كفت مداخله اجراشده با الخوى الخوى اعتقاد بهداشتى بهى

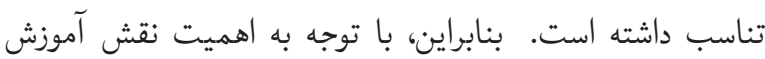

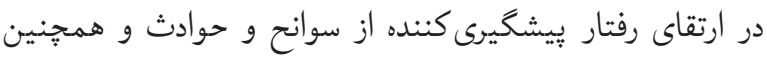
عوارض ناشى از آن (ازجمله مرگ، معلوليت دائمى و موقت)، و و

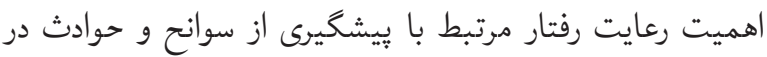

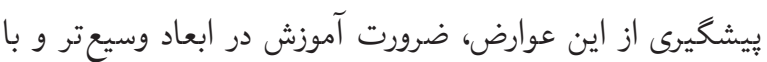
ابزارهاى مختلف در جامعه بيشازيّيش احساس مى گردد و بايد از

$$
\text { اولويتهاى بهداشتى در جامعه محسوب شود. }
$$

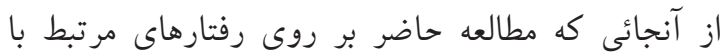

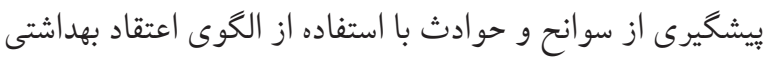

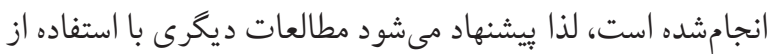

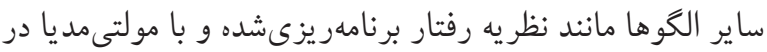
اين زمينه انجام شود.
بيانكر اين موضوع است كه ارائه آموزشهاى لازم به مادران جهت قبول منافع ناشى از اتخاذ رفتارهاى بيشگيرى كننده از سوانح و حوادث و غلبه آنان بر موانع موجود در زمينه اتخاذ رفتارهاى ييشخيرى كننده از سوانح و حوادث ضرورى هستيند.

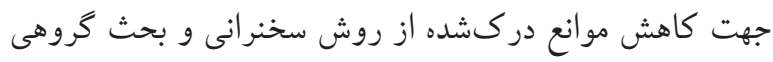

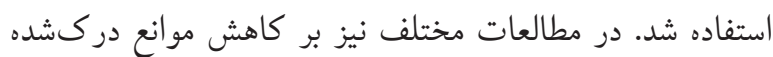

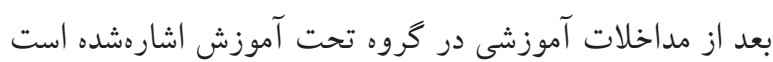

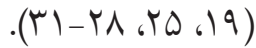
يافتهاى اين بُزوهش نشان داد كه ميانگين نمره

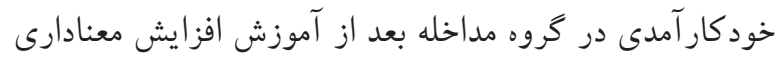

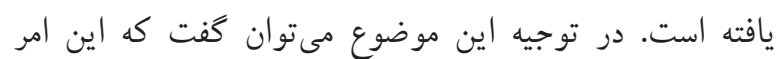
ناشى از اثربخشى مداخله آموزشى برنامهريزىشده در افزايش

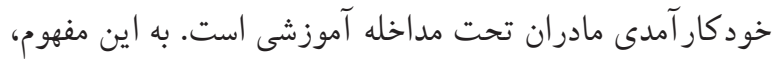

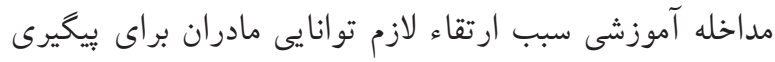
رفتار ييشخيرى كننده از سوانح و حوادث مىشود. ازجمله اين توانمندىها عبارتاند از: اطمينان مادر به خود كه مىتواند بر فعاليتهاى كودكش در هر زمان نظارت و توجه كافى داشته

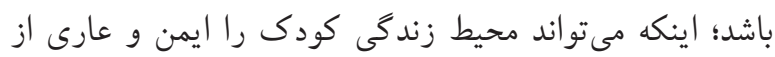

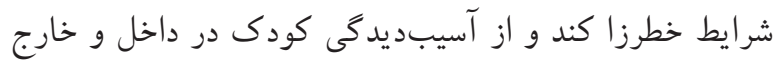
از منزل بيشخيرى كند. جهت افزايش خودكار آمدى از روش

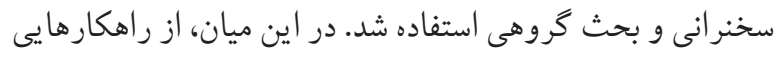

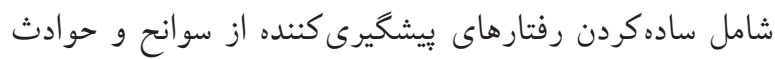
در كودى، تشويق كلامى و نوشتارى در كتابجه آموزشى و بيان

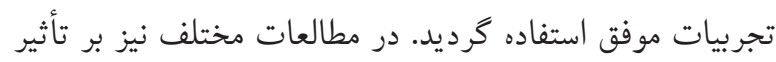

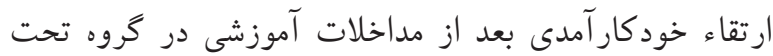

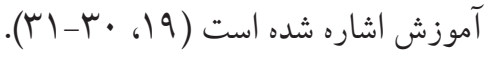

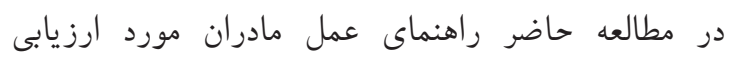

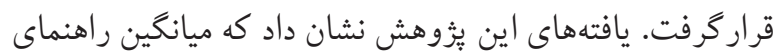

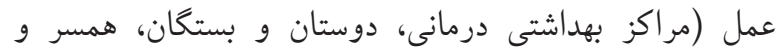

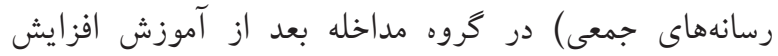

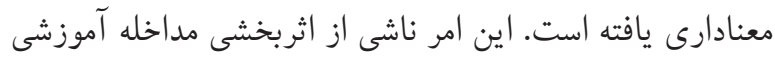




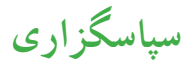

$$
\begin{aligned}
& \text { اين مقاله بركرفته از ياياننامه كارشناسىارشد آموزش بهداشت } \\
& \text { با كد تصويب آM در دانشعاه علوم يزشكى اراك است. } \\
& \text { بدينوسيله از كليه مادران شركت كننده در اين طرح و معاونت } \\
& \text { يُوهشى دانشخاه علوم يزشكى اراك كه طرح ياياننامه را مورد } \\
& \text { تصويب و حمايت مالى قرار دادند تقدير و تشكر مى گردد. }
\end{aligned}
$$

\section{References:}

1. Loghmani S, Tavallaie M, Haddadi F. Epidemiologic Features of Children with Burns Admitted to Imam Musa Kazem Hospital, Isfahan, Iran. Journal Of Isfahan Medical School.2012;29(169):44-50.

2. Tajedini F, Delbarpoor ahmadi S, Ehdaievand F, Moghimi dehkordi B, Torkaman nejad S, Farsar A. Epidemiological features of children mortality in the area covered by Shahid Beheshti university of medical sciences in 2012. Journal of Clinical Nursing and Midwifery. 2014; 3 (1):6271.

3. Khazaee T, Abdollahi F, Momeni R. Incidences Epidemiology in Children Referring to Emergency Centers of Birjand. Dena, Quarterly Journal of Yasuj Faculty of Nursing And Midwifery. 2009;4 (1-2):59-67. [Persian]

4. Poorolajal J, Cheraghi P, Hazavehei SM, Rezapur-Shahkolai F. Factors associated with mothers' beliefs and practices concerning injury prevention in under five-year children, based on health belief model. Journal of research in health sciences. 2012;13(1):63-68[Persian]

5. $\mathrm{Xu} \mathrm{YH,} \mathrm{Huang} \mathrm{XW,} \mathrm{Yang} \mathrm{RL.} \mathrm{The} \mathrm{under-five} \mathrm{mortality} \mathrm{rate}$ and the causes of death in Zhejiang

6. Province between 2000 and 2009. Zhongguo Dang Dai Er Ke Za Zhi .2011; 13(7): 561-4.

7. Ntuli S, Malangu N, Alberts M. Causes of deaths in children under - five years old at a tertiary Hospital in Limpopo province of South Africa. Global Journal of health and Science.2013; 5(3): 95-100.

8. sharaki Vahed A, mardani M, arab M, firoozkoohi Z. Infant under 1-59 month mortality causes in Zabol. IJNR. 2010; 5 (17):6-13[Persian]

9. Rostami $H$, Mirzaie $M$, Sadigh AL, Moayyed $H$, Mazaheri A, Mirzaie A. Home Eye Trauma in Emergency Units. Iran Journal of Nursing. 2006;18(44):15-22. [Persian]

10. Samimi R, Fatemi M J, Soltani M. The Epidemiological Assessment of Burn Injuries in Children Admitted to Mottahari Hospital, Tehran, 2009-2010. Iranian Journal of Surgery. 2011;19(1):24-29. [Persian]

11. khodam $\mathrm{H}$, mohammadian s, kolagari s. Epidemiologic Study of Acute Poiconing in Chidren Under 12 Years Old
همجنين بايد رسانها تشويق شوند تا رفتار مرتبط با ييشخيرى از سوانح و حوادث در كود كان را براى كاهش سوانح و حوادث در كودكان در جامعه ترويج نمايند. از برنامههاى اطلاعرسانى عمومى نظير بر گزارى نمايشخاهها در سطح جامعه بهمنظور افزايش سطح حساسيت عمومى نسبت به تأثير سوانح و حوادث در زندگى شخصى و اجتماعى كود كان نيز استفاده شود.

Refred to Taleghani Medical-Educational Centre of Gorgan Journal of Gorgan Bouyeh Faculty of Nursing \& Midwifery. 2005(7):34-39. [Persian]

12. Memarzadeh M, Hoseinpour M, Sanjary N, Karimi Z. A study on trauma epidemiology in children referred to Isfahan Alzahra Hospital during 2004-7. Feyz, Kashan University of Medical Sciences \& Health Services. 2011;14(5):488-493. [Persian]

13. Tehrani H, Majlessi F, Shojaeizadeh D, Sadeghi R, Kabootarkhani MH. Applying Socioecological Model to Improve Women's Physical Activity: A Randomized Control Trial. Iranian Red Crescent Medical Journal. 2016;18(3).

14. Vahedian-Shahroodi M, Elaheh L-m, Esmaily $H$, Tehrani $\mathrm{H}$, Hamidreza M-H. Prediction of osteoporosis preventive behaviors using the Health Belief Model. Iranian Journal of Health Education and Health Promotion. 2014;2(3):199207. [Persian]

15. Neghab M, Habibi M, Rajaeefard A, Choobineh A. Home Accidents in Shiraz during a 3-year Period (2000-2002). BEHBOOD. 2008;11(35): 428-440. [Persian]

16. Sajadi Hazaveyee M, Shamsi M. The effect of education based on Health Belief Model (HBM) in mothers about behavior of prevention from febrile convulsion in children. Scientific Journal of Hamadan Nursing and Midwifery Faculty. 2013:21(2): 37-46[Persian].

17. Shamsi M, Tajik R, Mohammad Beigi A. Effect of education based on Health Belief Model on self-medication in mothers refering to health centers of Arak. Journal of Arak University of Medical Sciences. Autumn 2009; 12(3): 44-53[Persian]

18. Karimi M, Zareban Ir, Montazrei A, Aminshokravi F. The Impact of Education Based On Health Belif Model In Preventive Behavior Of Unwanted Pregnancy. IJOGI.2012;15(23):18-27[Persian]

19. Karimi M, Ghofranipour F, Heydarnia AR. The effect of health education based on health belief model on preventive actions of aids on addict in zarandieh. Journal Of Guilan University Of Medical Sciences. 2009; 18(70):64-73[Persian] 
20. Jadgal Kh M, Zareban I, Rakhshani F, Alizade Siouki H, Lotfi Mayen Boulagh B,Hajilou E. The Impact of Health Education Based on Health Belief Model on Preventive Behavior of Unwanted Pregnancy among Chabahar Women. Journal of health and care. 2013:5(3):191-202. [Persian]

21. Rakhshani F, Esmaeili A, CharkaziA, HaftsavarM, Shahnazi $H$, Jan Esmaeili A. Effect of education on smoking prevention in students of Zahedan. Journal of Health System Research. 2010;6(2):267-75. [Persian]

22. Shamsi M, Sharifirad G, Kachoyee A, Hassanzadeh A. The Effect of Educational Program Walking Based on Health Belief Model on Control Suger in Woman by Type 2 Diabetics. Iranian Journal of Endocrinology \& Metabolism. 2010;11(5):490-499. [Persian]

23. Karimy $M$, Hasani $M$, Khoram R, Ghaffari M, Niknami SH. [The Effect of Education Based on Health Belief Model on Breast Self- Examination in Health Liaisons of Zarandieh City]. Zahadan Journal of Research in Medical Sciences.2008; 10(4):283-291. [Persian]

24. Kanga NM, Songb Y, Im EO. Korean university students' knowledge and attitudes toward breastfeeding: A questionnaire survey. Int J Nurs Stud. 2005; 42:863-870

25. Gilasi H, Babaee M, Gharlipour Gharghani Z, Heidarian M, Tavassoli E. The Effect of Health Education Based on Health Belief Model on Mother's Participation for Neonatal Hypothyroidism Screening Program. Iranian Journal of Endocrinology and Metabolism. 2013; 15 (3):285-291

26. Jahangiri L, Shojazadeh D, Khajeh Kazemi R, Dehi M, Karimi F Using of Health Belief Model in educational based program and its effect on knowledge and attitudes of women on breast cancer screening. Journal of Health System Research. 2011;7(6):1-9. [Persian]

27. Lin p, Simoni JM, Zemonv. The health belief model, Sexual behaviors, and HIV risk among Taiwanese immigrants. AIDS Educ Prev. 2005:17(5):469-483.

28. Asadpour M.Heydarnia AR. Promotion and maintenance of preventive behaviors from HIV, HBV and $\mathrm{HCV}$ infections in health care worker with using constructs of health belief model in Precede- Proceed model.Thesis for Doctorate in Health Education.Tarbiat Modares University;2011:151-232. [Persian]

29. Shojaezadeh D, Sadeghi R, Tarrahi M J, Asadi M, Lashgarara B. Application of Health Belief Model in Prevention of Osteoporosis in Volunteers of Khorramabad City Health Centers, Iran. Journal of Health System Research. 2012;8(2):1-10. [Persian]

30. Pirzadeh A. The effect of health education based on health belief model on performance of women regarding Pap smear test in Kouhdasht health centers in 2010. Journal of Health System Research.2010;6(2):365-372. [Persian]

31. HosseinTaghdisi M, Nejadsadeghi $E$. The effect of health education based on health belief model on behavioral promotion of urinary infection prevention in pregnant women. Journal of Research \& Health. 2012; 2(1):126136. [Persian]

32. Karami K, Shakerinejad G, Kabiry B. Effect of education based on health belief model on the alteration of oral health behaviors among students. Scientific Journal of Ilam University of Medical Sciences. 2013;21(7):134-141. [Persian] 